\title{
Editorial: Being and Becoming a Teacher in Neoliberal Times
}

\author{
Magnus Levinsson, University of Borås, Sweden. \\ Email:magnus.levinsson@hb.se
}

Andrew Foran, St. Francis Xavier University, Canada.

Email:aforan@stfx.ca

It is...advisable that the teacher should understand, and even be able to criticize, the general principles upon which the whole educational system is formed and administered. He [or she] is not like a private soldier in an army, expected merely to obey, like a cog in a wheel, expected merely to respond and transmit external energy; he [or she] must be an intelligent medium of action.

John Dewey (1895)

According to Dewey in 1895 (as cited in Jefferson \& Anderson, 2017), and later other pragmatists, the hope of a better and more democratic society, rests on teachers' ability to act more informed - or "intelligent"-in pedagogical practice. The exercise in using thinking as an instrument in experimental action is key in Dewey's educational manifesto. To allow intelligent action to develop, teachers require access to incentive and autonomous scholastic environments in which productive reflection on teaching is possible. In this reflective process, complex experiences from pedagogical encounters are developed and improved; the teacher will reason more intelligently and subsequently act more intelligently. However, since Dewey's comment, more than a century ago, years of institutionalized education have solidified a global hold on how children and young people are schooled. This comparative and competitive educative process has impacted the teacher's world; absorbing educators' everydayness in competing professionalized tensions and pressures of standardization. As guest editors for Phenomenology \& Practice, we explore what this hold has meant to becoming and being a teacher post-Dewey. The evolution of teacher education has seen the Western part of the world ignoring pedagogical practices in teacher preparation in favor of government initiatives that promote the value of testing scores, government-controlled curricula, assessment-driven practices, and evidence-based teaching programs. 
For the last 25 years, this regulatory grip on schooling has been strongly fueled by the implementation of pervasive neoliberal policies. Ball (2016) identifies three key components, or "technologies" (p. 1049), in the neoliberal reform process-Market, Management and Performance - which have dramatically changed what it means to be a teacher at all levels of the education system:

They change what it means to be educated, what it means to teach and learn, what it means to be a teacher. They do not just change what we do; they also change who we are, how we think about what we do, how we relate to one another, how we decide what is important and what is acceptable, what is tolerable...these changes are both out there, in the system, the institution; and 'in here', in our heads and in our souls. (p. 1050)

According to Ball (2016), the impact, pace and intensity of the neoliberal reform process varies between countries due to contextual and site-specific conditions. However, in the Western part of the world, this ideological and political restructuring of education has resulted in dramatic increases in the following areas: bureaucratic control, commodification, inequality, accountability, and performativity - under the guise of universal standards, but with political intentions of controlling education.

Teacher education and public-school teaching have shifted from building a practice on relational encounters with pupils in order to help them grow-and in hope of forming a better world - to that of being a manager directing narrow and decontextualized learning services, largely controlled by others, to produce measurable outcomes that are high currency at the competitive school market. Thus, teachers have been reduced to managerial drones - "like a cog in a wheel," to return to Dewey's metaphor - expected merely to operate and uncritically serve the neoliberal agenda. The result: teachers are largely being turned away from the question of purpose in education, and from the personal and non-professional significance implied in the term pedagogy. Teachers, in all stages of their careers, can testify how the nature of their professional duties and identities has dramatically changed due to the neoliberal assault on their work. The consequences of these transformations are devastating; there are alarming reports of teachers choosing to leave the profession due to the growing burden of administration and documentation, and due to the increased emphasis on testing, evaluation, and inspection.

By reviving a pedagogical practice in teacher education, and exploring the lived experiences of teachers, phenomenology can position pedagogical priorities that value the relationality between teachers and pupils, in order to fulfill complex educational purposes, over government-imposed norms and measurable academic outcomes. A phenomenological examination will challenge a commodified, outcome-based and assessment-driven education that is not oriented to an open future for the child but forecloses on multiple possibilities by insisting on pre-established criteria and performance standards.

The focus of this Special Issue is to explore what it means to be teacher in the $21_{\mathrm{st}}$ century - an era dominated by neoliberal reform processes. The authors in this Special Issue responded to our call, Being and Becoming a Teacher in Neoliberal Times, from two years ago and decided to stand up, use their voices, collectively to not only reveal that the increased neoliberalism has profound consequences for the fundamental structure of a teacher's 
lifeworld, but also to assert that there is a way to teach, and to be a teacher that counters the neoliberal turn in education. Is this not what Dewey was professing in 1895? The authors draw on lived experiences of how neoliberalism has influenced teacher education and publicschool teaching in Canada, Norway, Sweden, and the United States of America, and through a variety of phenomenological approaches, they address the complexity of what it means to be and become a teacher in a neoliberal era.

Levinsson, Norlund, and Beach addresses the call, in Teacher Educators in a Neoliberal Time: A Phenomenological Self-Study, by presenting their everyday experiences of being educators, immersed in a teacher education culture in Sweden, which has evolved under the pressures of neoliberalism. The phenomenological first-person accounts shared in the article show that the neoliberal turn in Swedish teacher education has substantial consequences for the fundamental structure of a teacher educator's lifeworld. The practices that have emerged in the wake of the Bologna process and New Public Management bring about significant spatial, bodily, temporal, and relational experiences that hardly can be associated with "autonomous teacher educators who are guided by professional judgement and responsibility." Rather, they reflect teachers who are being turned away from education, and whose professional duties and identities are being fundamentally changed. The authors call for joint resistance among educators to bring about change within Swedish teacher education.

Henricsson's article, Student Teachers' Storytelling: Countering Neoliberalism in Education, is a unique portrayal of the power of storytelling in Swedish teacher education and his work serves as a counter-point to the dominance of neoliberalism. The latest reform in Swedish teacher education has positioned future teachers as responsible only for communicating official school knowledge and assessing the learning process. According to Henricsson, this narrowed understanding of a teachers' practice requires another perspective on teaching to be articulated. Henricsson explores the internships of beginning teachers from a phenomenological perspective, and draws on storytelling as a way to reveal student teachers' lived experiences: "these beginning teachers are learning professional ways of being, which reveal the complexities of teaching." The storytelling accounts explored in the article open up educational discourse to what is possible in countering and deconstructing the infiltration of neoliberalism in public school teaching and teacher education.

Foran, Robinson, Munroe, Eilifsen, and Thurber's article, Pedagogy: A Teacher's Practice, lead us to see how the pedagogical use of the outdoors in Norway can disrupt the institutional neoliberal hold on Canadian preservice teachers' practice allowing for relational possibilities that governments cannot control, manufacture or produce on demand:

These preservice teachers acknowledged that every educational act, and relational encounter, is subtended by tensions and uncertainty. ...They presented what they experienced about teaching and embraced the ambiguities of being with children and young people...this was possible because teaching was removed from institutional and imposed instructional mandates. In this Norwegian teaching space, these beginning teachers were able to reclaim pedagogy as practice where pupils and teachers "belong." 
The insights of becoming teachers, shared in the article, maintain pedagogy as an intuitive and responsive practice that is child-based on relationality, not metrics.

Bredmar explores how the increased influence of neoliberalism in education has allowed the trend of evidence-based teaching to dominate teachers' professional development. However, in Developing Sensitive Sense and Sensible Sensibility in Pedagogical Work, Bredmar investigates the phenomenon of emotions in teacher reflections, drawing on lifeworld theory, and she reveals how emotional experiences can be a powerful resource in a teacher's learning process. According to Bredmar, professional development through reflection on emotional experiences "implies a quite different position for the teacher, not as the one who is there to realize evidence-based directives formulated elsewhere, but as the one who plays a central role in engaging with what is educationally desirable and required in each concrete situation."

Babulski's view from the United States of America presents a historical overview of the erosion of social justice in Being and Becoming Woke in Teacher Education. In the past several decades, the rise of neoliberalism in American education politics has shifted the balance away from equity, diversity, and inclusivity. The purpose of this study is to provide an account of the lived experiences of teacher candidates with the phenomena of being and becoming "woke" within a teacher education program that reflects neoliberal values but maintains a stated commitment to social justice. Babulski offers narrative vignettes that explore the phenomenality of wokeness as it manifests in the public-school environment and the teacher education program. He also addresses the effects of neoliberalism on teacher candidates' willingness and ability to take up social justice for themselves, their students, and society.

Professional Ethics as Experienced by Student Teachers is examined by Cronqvist, and this view from Swedish teacher education points to another educational dimension under attack. Neoliberal currents have prompted a focus on teaching ethics - different to teaching ethically_which is closely aligned with the growing accountability regime. However, inspired by a Reflective Life World Research approach, Cronqvist explores what professional ethics means for becoming teachers based on their lived experiences from internships. The essential meanings of professional ethics are interpreted in light of the professional tensions that are emerging from neoliberal influences: "Student teachers' learning to teach ethically takes place in the field of tension between responsibility and accountability." Cronqvist shows that by identifying the implications of professional ethics in neoliberal times, teacher educators will be able to observe the manifestations this has for teaching, and foster student teachers' learning of professional ethics accordingly.

Rinne's discussion, Pedagogic Being in a Neoliberal School Market, explores teaching through her own lived experiences of becoming and being an upper secondary school teacher over a period of 25 years, when neoliberal policies gradually changed the conditions for teaching in Swedish schools. These transformations challenged her development of pedagogical tact, and created tensions between her pedagogical orientation and the educational practices influenced by neoliberal ideals. Drawing on a lifeworld phenomenological approach, carried out through personal narrative, Rinne offers lived experience descriptions that uncovers a disturbing tension. Schooling was moving in a 
direction that can be summarized in the following statement: "shape students for the needs of the market." This mantra was in keeping with neoliberal policy in positioning the educational focus to be limited on skills and competencies, in order to make the students more employable. Therefore, students did neither acquire basic knowledge in core school subjects nor develop critical thinking. Consequently, in response, the teacher too became evermore narrow and market-driven, instead of more pedagogically tactful.

In this Special Issue, under Phenomenological Notes, we have an interesting interview and discussion provided by Sandvik. This work was part of his Masters of Pedagogy thesis, conducted at the NLA University Collage in Norway, where Sandvik explored freedom and pedagogical freedom. Phenomenological Notes shares a segment of the interview with Professor Jan Masschelein that focused on pedagogical freedom. This conversation is not only informative for those interested in pedagogy, but Masschelein's words have a direct professional impact on all those involved in education and teacher development. At the end of the interview, Sandvik critically reflects on the conversation with Masschelein, and the lessons learned are discussed in light of the neoliberal realities facing Norwegian teachers.

Finally, this Special Issue has a poignant review of The Rediscovery of Teaching, one of Biesta's latest works pertinent to those interested in educational issues and practices. Reading the book inspired Saevi to write a response, rather than a traditional book review: "For this response I want a presentation that opens the reader up to relevant questions and concerns in education, as well as an expression of my personal replies and critical concerns regarding this text." According to Saevi, this book opened her "eyes to what teaching is, or said differently, it taught [her] that teaching might more importantly address the student." The personal reflections offered by Saevi in this book review are closely aligned with the theme of this Special Issue, and carry important messages for teachers who confront neoliberal agendas.

As co-editors of this Special Issue, it is our hope that you can identify with these voices from classrooms, and reflect deeply on the shifting landscapes in education and what they mean for teachers. Extending this thinking, and coming back to 1895, what does this mean for pupils and students and their possibilities to form the next generation of democratic citizens. During these two years, in guiding this Special Issue, we have discovered that despite the dominance of neoliberalism, the spirt of what it means to be a teacher is still there, strong and existing, represented here as lived experiences. These authors have offered a range of powerful insights countering the destructive political force of neoliberalism. The lived experiences shared in this Special Issue revealed a collective effort of resistance shown by: thoughtful storytelling in teacher education, visiting teaching spaces that allow teachers to reclaim pedagogy as practice, professional learning through reflection on emotional experiences, becoming woke to social injustices, balancing accountability against professional responsibility, and developing and exercising pedagogical tact. Through this Special Issue we hope to contribute to teachers' know-how and know-why around the globe who are facing neoliberal realties in public school teaching and teacher education; that the phenomenological accounts offered by these authors will empower them to act more informed - or "intelligent" - in line with Dewey's vision, and "even be able to criticize, the general principles upon which the whole educational system is formed and administered. 


\section{References}

Ball, S. J. (2016). Neoliberal education? Confronting the slouching beast. Policy Futures in Education, 14(8), 1046-1059.

Jefferson, M., \& Anderson, M. (2017). Transforming schools: Creativity, critical reflection, communication, collaboration. London: Bloomsbury Publishing. 